\title{
Sabrina MERVIN, Nabil MOULINE, Islams politiques. Courants, doctrines et idéologies
}

Paris, CNRS Éditions, 2017, 231 p.

\section{Rachida Chih}

\section{(2) OpenEdition} Journals

Édition électronique

URL : https://journals.openedition.org/assr/34025

DOI : $10.4000 /$ assr.34025

ISSN : 1777-5825

Éditeur

Éditions de l'EHESS

Édition imprimée

Date de publication : 1 décembre 2017

Pagination : 396-397

ISSN : 0335-5985

\section{Référence électronique}

Rachida Chih, «Sabrina mERvin, Nabil mouline, Islams politiques. Courants, doctrines et idéologies », Archives de sciences sociales des religions [En ligne], 180 | octobre-décembre 2017, mis en ligne le 01 décembre 2017, consulté le 22 septembre 2021. URL : http://journals.openedition.org/assr/34025 ; DOI : https://doi.org/10.4000/assr.34025

Ce document a été généré automatiquement le 22 septembre 2021.

(c) Archives de sciences sociales des religions 


\title{
Sabrina MERVIN, Nabil MOULINE, Islams politiques. Courants, doctrines et idéologies
}

Paris, CNRS Éditions, 2017, 231 p.

\author{
Rachida Chih
}

\section{RÉFÉRENCE}

Sabrina MERVIN, Nabil MOULINE, Islams politiques. Courants, doctrines et idéologies, Paris, CNRS Éditions, 2017, 231 p.

1 Dans les années 1980, des chercheurs et universitaires avaient popularisé en France le terme islamisme pour décrire des courants et mouvements politiques qui cherchent à imposer la loi islamique, la sharia comme fondement de l'État: leurs travaux, qui mêlent enquêtes de terrain et réflexion théorique, donnent à la recherche française dans ce domaine une renommée internationale. Majoritairement politistes, ils ont cherché à étudier l'islam sous l'angle des sciences sociales à contrecourant des orientalistes qui ne l'avait appréhendé que par l'étude des textes sacrés. Islams politiques part d'un constat: la dimension religieuse a longtemps été occultée par la recherche académique au profit des facteurs politiques et socio-économiques; et affiche un objectif: il est nécessaire de tenir compte du «théologico-politique» si l'on veut comprendre les situations et les enjeux dans les crises qui secouent le monde musulman contemporain. Quant à la trame de ce volume collectif, elle consiste à prendre tout un chapelet de termes en "isme " inventés par l'orientalisme puis la recherche occidentale sur l'islam: réformisme, wahhabisme, fondamentalisme, djihadisme, salafisme, chiisme, zaydisme, soufisme, ismaélisme, ibadisme afin de les déconstruire à la lumière des avancées historiographiques. La méthode privilégie l'histoire, partant du postulat que les questions d'autorité et de pouvoir en islam s'inscrivent sur la longue durée, et prend comme point de départ le xix ${ }^{e}$ siècle quand le 
monde musulman entre en contact direct avec l'Europe impérialiste. Aux penseurs et politiques musulmans s'était alors posée une question cruciale : comment concevoir les conceptions politiques modernes apportées par l'Occident avec l'islam?

2 Les responsables du recueil sont tous deux historiens de l'islam contemporain, le premier de son courant majoritaire, le sunnisme, et plus particulièrement $\mathrm{du}$ wahhabisme; quant à la seconde, elle est spécialiste du chiisme duodécimain contemporain. Ensemble ils ont dirigé à l'Iismm (Institut d'études de l'Islam et des sociétés du monde musulman) un séminaire d'enseignement interdisciplinaire, Doctrines et pratiques de l'islam contemporain (XIXe-XXI siècle), avec pour mission d'initier les étudiants aux textes de l'islam et à leur mise en contexte, au dogme et aux pratiques en faisant appel aussi bien à l'histoire qu'à l'anthropologie, à la philologie qu'aux sciences sociales. Ils ont sollicité pour contribuer à ce recueil une nouvelle génération de chercheurs qui assure brillamment la relève de leur aînés : excellents linguistes et aguerris à des terrains pourtant de plus en plus dangereux, ils perpétuent et renouvellent un champ de recherche bien français.

3 Les 11 articles du recueil sont de longueur et de teneur inégale : les courants fondateurs font l'objet de solides synthèses (A. Jomier, Les réformismes musulmans; N. Mouline, Les prétentions hégémoniques du wahhabisme; Le djihadisme, à la recherche du califat perdu; $\mathrm{S}$. Lacroix, L'islamisme au prisme des Frère musulmans; S. Mervin, Autorité religieuse et pouvoir politique dans le chiisme duodécimain; Les alaouites en Syrie) alors que les communautés minoritaires de l'islam ou des formes plus localisées sont réduites à de simples notices (A. Philippon, Soufisme et politique au Pakistan; L. Al Rachid, Un soufisme caméléon? La Naqshbandiyya de Saddam Hussein à l'État islamique; S. Dorlian, Le zaydisme: dilemme d'une dénomination marginale; A. Jomier, L’ibadisme, un islam méconnu; M. Boivin, Politique de l'imamat ismaélien, Karim Aga Khan et son "état virtuel»).

Dans le titre de l'ouvrage, le terme islamisme, souvent accaparé par les médias et les politiciens jusqu'à devenir un concept fourre-tout ouvert à tous les amalgames, est abandonné au profit de celui d'islam politique; il n'en est, en fait, qu'un synonyme et comme islamisme il pose problème à partir du moment ou il contient le mot « islam ». On ne parle plus non plus d'islamisme ou d'islam politique au singulier car il est désormais acquis qu'il existe une diversité de mouvements et de modes d'action en constante évolution, changeant au gré des évènements et de l'actualité, souvent de manière imprévisible (Olivier Roy n'avait-il pas prédit l'échec de l'islam politique en 1992 ? Et Gilles Kepel celui de son déclin en 2000, soit un an avant les attentats du 11 septembre?): les coordinateurs du recueil préfèrent parler de "configurations complexes, labiles et plastiques ».

5 En ce qui concerne l'objectif de départ du recueil, expliquer la dimension théologique des islams politiques, quelle conclusion peut-on tirer de l'ensemble des contributions? Les articles sur les réformismes, le wahhabisme et les Frères musulmans reviennent sur la genèse de ces mouvements et montrent qu'ils ont dès le départ des projets politiques différents même s'ils partagent un socle commun, à savoir une approche contestatrice et totalisante de la religion : ils nourriront divers courants qui feront par la suite de l'islam non plus une religion mais une idéologie. On constate combien ces courants empruntent leurs symboles et leurs concepts à l'Occident, surtout à partir de Sayyid Qutb (intellectuel égyptien, membre de la confrérie des Frères musulmans, torturé puis exécuté sous Nasser) dans les années 1960 : ce dernier enrobe d'un vernis religieux des idées marxistes, anti-impérialistes et révolutionnaires. La sociologie de ces intellectuels 
bricoleurs a été bien étudiée en France. Les islamismes sont des phénomènes modernes qui empruntent surtout à l'Occident dont ils sont le produit et peu à l'islam en tant que religion: dans tous les cas de figure exposés dans les diverses contributions, la référence religieuse n'est brandie que pour servir des intérêts politiques de groupes écartés du pouvoir ou bien pour diviser pour mieux régner, une pratique qui avait été constamment appliquée par les colonisateurs Anglais et Français. Rien de nouveau dans cet ouvrage qui n'ait déjà été démontré par les contributeurs eux-mêmes dans d'autres de leurs travaux.

6 Mais la nouveauté n'est pas l'objectif de cet ouvrage qui semble plus répondre à une demande conjoncturelle des pouvoirs publics et des éditeurs. Islams politiques est un livre de synthèse destiné aux étudiants, aux enseignants et à un large public. Dans une langue claire, précise et avec une pédagogie remarquable il résume les apports et les renouvellements historiographiques et rend accessible aux non-spécialistes un domaine d'étude complexe (sans pour autant sacrifier à l'érudition). Une bibliographie, des cartes de la répartition de la population musulmane dans le monde, une liste de dates importantes depuis l'hégire en 622 aux attentats de 2015-2016 complètent l'ouvrage. Les textes traduits en encadrés des fondateurs et penseurs de courants idéologiques (Muhammad 'Abd al-Wahhâb, Hasan al-Bannâ, Sayyid Qutb et des textes de l'État islamique) sont un autre atout majeur de ce très bon manuel. 